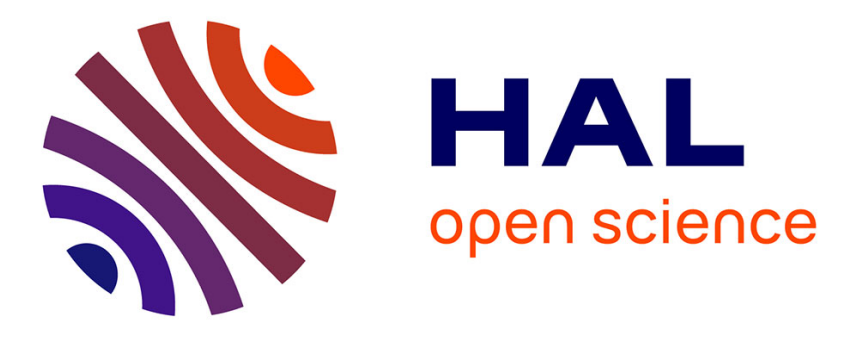

\title{
Not as bad as it seems: When the presence of a threatening humanoid robot improves human performance
}

Nicolas Spatola, Clément Belletier, Alice Normand, Pierre Chausse, Sophie Monceau, Maria Augustinova, Vincent Barra, Pascal Huguet, Ludovic Ferrand

\section{To cite this version:}

Nicolas Spatola, Clément Belletier, Alice Normand, Pierre Chausse, Sophie Monceau, et al.. Not as bad as it seems: When the presence of a threatening humanoid robot improves human performance. Science Robotics, 2018, 3 (21), pp.eaat5843. 10.1126/scirobotics.aat5843 . hal-02324232

\section{HAL Id: hal-02324232 \\ https://hal.science/hal-02324232}

Submitted on 26 Oct 2019

HAL is a multi-disciplinary open access archive for the deposit and dissemination of scientific research documents, whether they are published or not. The documents may come from teaching and research institutions in France or abroad, or from public or private research centers.
L'archive ouverte pluridisciplinaire HAL, est destinée au dépôt et à la diffusion de documents scientifiques de niveau recherche, publiés ou non, émanant des établissements d'enseignement et de recherche français ou étrangers, des laboratoires publics ou privés. 


\title{
Not as bad as it seems: When the presence of a threatening humanoid robot improves human performance
}

\author{
Nicolas Spatola ${ }^{1}$, Clément Belletier ${ }^{2}$, Alice Normand ${ }^{1}$, Pierre Chausse ${ }^{1}$, Sophie \\ Monceau $^{1}$, Maria Augustinova ${ }^{3}$, Vincent Barra ${ }^{4}$, Pascal Huguet ${ }^{*}{ }^{1}$, Ludovic Ferrand ${ }^{*}{ }^{1}$ \\ ${ }^{1}$ Université Clermont Auvergne, CNRS, LAPSCO, F-63000 Clermont-Ferrand, France \\ ${ }^{2}$ Laboratoire Psychologie du Développement Cognitif, Université de Fribourg, Switzerland \\ ${ }^{3}$ Normandie Université, UNIROUEN, CRFDP, F-76000 Rouen, France \\ ${ }^{4}$ Université Clermont Auvergne, CNRS, LIMOS, F-63000 Clermont-Ferrand, France
}

*Co-last authors

Summary: Bad Humanoid robots just paying attention to human performance may energize attentional control—as also does human presence. 
Millions of people worldwide may soon benefit from the presence of humanoid robots designed to ensure support to the elderly, disabled people or pupils with learning difficulties [1]. Despite this unstoppable trend, little is known about the emotional experience associated with Human-Robot Interaction (HRI) and its impact on human cognition. Because this is a critical issue for the introduction of humanoid robots in our societies [2], we examined here for the first time whether a) socially interactive humanoid robots impact attentional control (i.e., the paramount cognitive ability); and b) this impact depends on the emotional valence associated with HRI. To do so, we used the gold standard of attentional measures, the Stroop task [3], requiring individuals to identify the color in which a word is printed, ignoring the word itself. Because of the automaticity of reading, identification times are consistently longer for color-incongruent words (the word "BLUE" in green ink) than for color-neutral items ("DESK" in green ink). The amplitude of this well-known effect, called "Stroop interference", indicates the efficiency of cognitive-attentional control. It yet typically decreases under stress [4], especially in presence of others competing with — or simply paying attention to-our current performance [5, 6, 7]. However, whether and when exactly the presence of social humanoid robots also boosts attentional control remains unanswered. We predicted that even the presence of robots simply paying attention to human performance may energize attentional control—as also does human presence, especially when these robots are thought to be likely to produce negative evaluations [8].

To test this hypothesis, young adults performed the standard Stroop task twice. In Session 1, all participants performed the task alone. In Session 2, they performed the task either alone or in the presence of a humanoid robot with which they had previously interacted either positively — a good robot responding in a nice way, with empathy —or negatively — a bad robot responding with contempt, a lack of empathy, and producing negative evaluations about participants' intelligence (see supplementary materials). In the two robotic presence 
conditions, the robot was animated at distance using two smartphones for the control of its gestures and speech based on a strictly identical script (e.g., head movement toward the participant $60 \%$ of the time, light arm movements) (Figure 1). At the end of Session 2, participants in the two robotic conditions rated the robot being present on various personality traits (see supplementary materials), either positive (e.g., warm, competent) or negative (awkward, aggressive).

\section{INSERT FIGURE 1}

Figure 1. - Panel A presents the experimental installation. We used a Meccanoid ${ }^{\mathrm{G} 15 \mathrm{KS}}$ animated at distance by a human operator using two smartphones for the control of the robot's gestures and speech. In the two presence conditions, the robot was positioned in front of participants (to their right on the edge of their peripheral vision) and watched them $60 \%$ of the time by turning the head according to a pre-established script. -

Not surprisingly, the bad robot was rated as less warm, friendly and pleasant than the good robot. Participants also attributed less Human Nature traits (e.g. "Cognitive openness") and more Mechanical Dehumanization (e.g. "Rigidity") traits to the bad robot than to the good robot (see supplementary materials). More importantly, individuals' attentional control improved dramatically under the presence of the bad robot. Planned comparisons were used to analyze relevant between-group contrasts (alone vs. pleasant robot; alone and pleasant social robot averaged vs. unpleasant social robot) on Stroop interference (RTs for color-incongruent words minus RTs for color- neutral items) at Session 2 minus interference at Session 1 (baseline). A positive value (see Figure 2) means reduced interference (improved performance) at session 2 relative to baseline. As expected, Stroop performance improved exclusively in the presence of the unpleasant robot. This critical condition differed from the two other conditions averaged (alone and pleasant social robot), which did not differ from one another (see supplementary materials for detailed statistical analyses). 


\section{INSERT FIGURE 2}

Figure 2. It illustrates the main effect of condition on Stroop performance improvement (in ms, error bars represent 1 standard error) showing that the positive interaction condition did not differ from the control condition whereas the negative HRI condition differed from the positive HRI and control conditions averaged (see supplementary materials for detailed statistical analyses).

These findings run counter a purely mechanistic approach reducing the effects of robotic presence to the action of physical or noise distraction, which may sometimes facilitate as well as inhibit performance depending on task difficulty [9]. According to this approach, both robotic presence conditions should have conducted-regardless of their emotional tone (positive or negative) - to a performance change, compared with isolation (all the more so than the robot's appearance and behavior during task performance were strictly identical in both conditions). Instead, Stroop performance changed exclusively in the bad social robot condition. Perhaps even more striking, the bad social robot had exactly the same impact on Stroop performance as in earlier research with human presence [5, 6, 7]. This presence reduced-rather than increased-Stroop interference, which extends the relevance of the attentional view of social facilitation from humans to social robots. According to this view [5, 6], the presence of potentially threatening others improves the selectivity of attention to relevant information at the expense of competing cues (in the Stroop task the color in which a word is printed at the expense of the word itself). This is exactly what happened in the bad social robot condition. Therefore, not only the behavior of robots can change humans' perception of robots during HRI [10], but these attributions are susceptible to make the simple presence of robots likely to impact human cognition as a function of the type of interaction.

Thus, the present findings constitute the first evidence that the presence of social robots may energize attentional control, especially when the emotional valence and 
anthropomorphic inferences associated with the robot being present requires a heightened state of alertness.

\section{References}

1. T. Kanda, H. Ishiguro, Human-robot interaction in social robotics (CRC Press, 2017).

2. G. Z. Yang, J. Bellingham, P. E. Dupont, P. Fischer, L. Floridi, R. Full, N. Jacobstein, V. Jumar, M. McNutt, R. Merrifield, B. J. Nelson, B. Scassellati, M. Taddeo, R. Taylor, M. Veloso, Z. L. Wang, R. Wood, The grand challenges of Science Robotics. Sci. Robotics 3, eaar7650 (2018).

3. C. M. MacLeod, The Stroop task: The "gold standard" of attentional measures. J. Exp. Psychol.: Gen. 121, 12-14 (1992).

4. E. Chajut, D. Algom, Selective attention improves under stress: implications for theories of social cognition. J. Pers. Soc. Psychol. 85, 231-248 (2003).

5. P. Huguet, M. P. Galvaing, J. M. Monteil, F. Dumas, Social presence effects in the Stroop task: Further evidence for an attentional view of social facilitation. J. Pers. Soc. Psychol. 77, 1011-1023 (1999).

6. D. Sharma, R. Booth, R. Brown, P. Huguet, Exploring the temporal dynamics of social facilitation in the Stroop task. Psychon. Bull. Rev. 17, 52-58 (2010).

7. M. Augustinova, L. Ferrand, The influence of mere social presence on Stroop interference: New evidence from the semantically-based Stroop task J. Exp. Soc. Psychol. 48, 1213-1216 (2012).

8. A. Normand, J. C. Croizet, Upward social comparison generates attentional focusing when the dimension of comparison is self-threatening. Soc. Cogn. 31, 336-348 (2013).

9. Baron, R. S., Distraction-conflict theory: Progress and problems, in Advances in experimental social psychology, L. Berkowitz, Ed. (Academic Press, 1986), vol. 19, pp. 1-40.

10. E. Broadbent, B. MacDonald, L. Jago, M. Juergens, O. Mazharullah, O, Human reactions to good and bad robots, in Proceedings of the IEEE/RSJ International Conference on the Intelligent Robots and Systems (2007), pp. 3703-3708. 


\section{Acknowledgments}

Funding: This work was supported by a grant (Social_Robot_2017-2018) from the Maison des Sciences de l'Homme (MSH), Clermont-Ferrand, France.

\section{Ethical statement}

This study was carried out in accordance with the provisions of the World Medical Association Declaration of Helsinki.

\section{Supplementary Materials}

Additional supporting information can be found at Supplementary Materials (Online Resource $1)$.

\section{Data and materials availability}

All data are publicly available via the Open Science Framework and can be accessed at osf.io/djgqh

\section{Corresponding authors:}

Nicolas Spatola or Ludovic Ferrand

CNRS and Université Clermont Auvergne

Laboratoire de Psychologie Sociale et Cognitive (LAPSCO - UMR CNRS 6024)

34, avenue Carnot

63037 Clermont-Ferrand

FRANCE

E-mail: Nicolas.spatola@uca.fr ; Ludovic.ferrand@uca.fr

Phone: + 33699729467

Fax: + 33473406114 
Science Robotics (2018).



Figure 1. 
Science Robotics (2018).

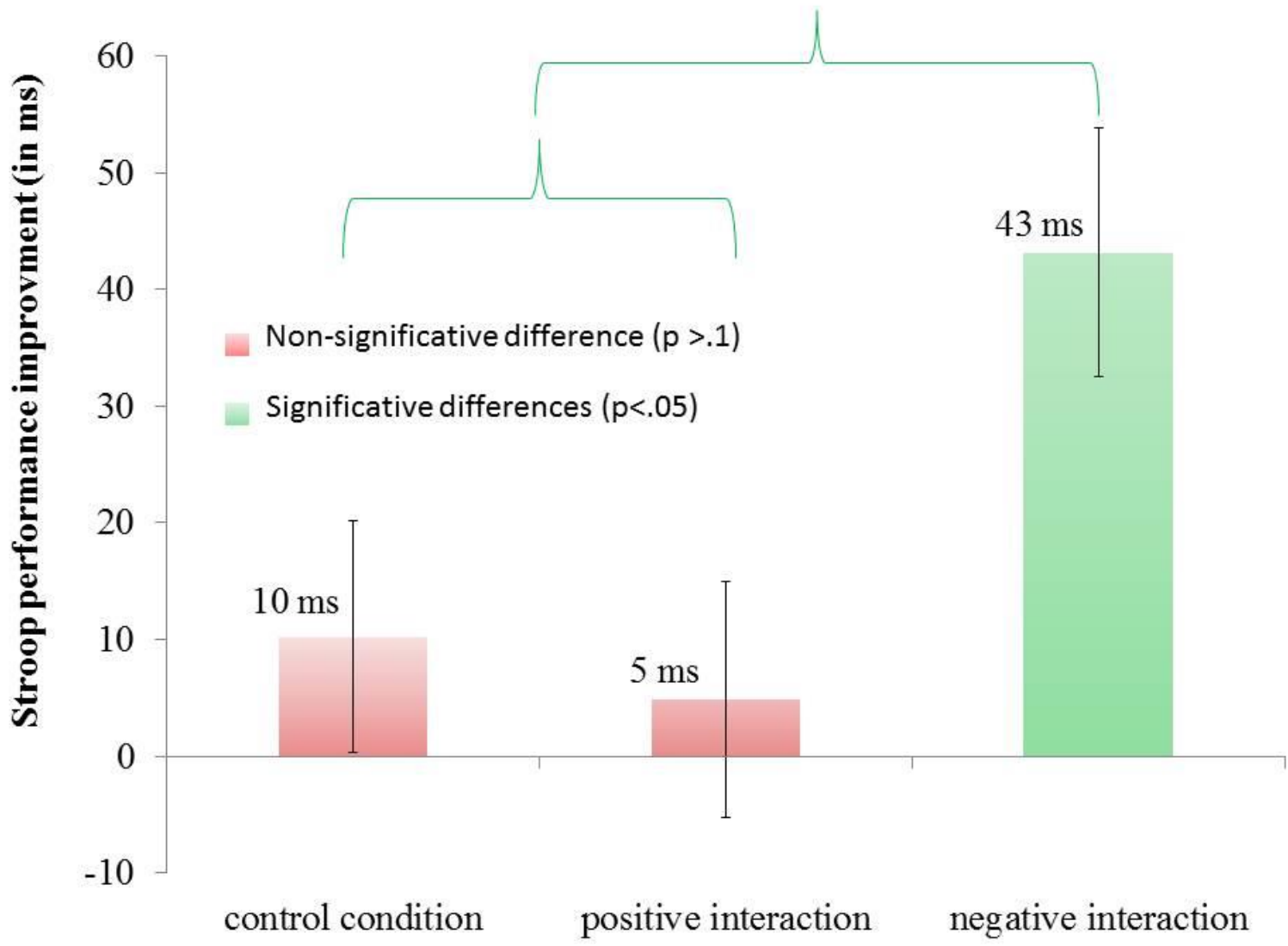

Figure 2. 


\section{Supplementary Materials}

\section{Methods}

\section{Participants}

Participants were 58 students from Université Clermont Auvergne, France $\left(M_{\mathrm{age}}=19.1\right.$ years, $\mathrm{SD}=0.96$ ) with normal (or corrected-to-normal) vision.

\section{Material}

The robot. The robot used was a 1-meter Meccanoid ${ }^{\mathrm{G} 15 \mathrm{KS}}$ humanoid, as we assumed that even robots with a basic humanoid appearance without emotional facial expression can be anthropomorphized [1]. It was (without participants' knowledge) animated at distance by a human operator using two smartphones for the control of the robot's gestures and speech (by selecting pre-established conversational scripts) in a coherent way ("Wizard of Oz paradigm" [2]), a condition encouraging anthropomorphic inferences and familiarity towards the robot [3]. After the experiment, none of the participants declared being suspicious about the robot's interactivity.

Stroop stimuli. Two types of stimuli were used: standard color-incongruent words (e.g., BLUE in green) and color-neutral words (e.g, DESK in green). The stimuli (presented in lowercase 18-point Courier font on a black background) consisted of four color words (rouge [red], jaune [yellow], bleu [blue], and vert [green]) and four color-neutral words (balcon [balcony], robe [dress], pont [bridge] and chien [dog]). In each condition, all the stimuli were similar in length (4.5 and 4.75 letters on average for the color-incongruent words and the color-neutral words) and frequency (74 and 84 occurrences per million for the colorincongruent words and the color-neutral words, respectively) according to the French lexical database Lexique [4]. Color-incongruent items always appeared in colors that were incongruent with the meaning of their word-dimension. There were 48 trials for each Stimulus-type factor condition, whose presentation order was randomly determined for each participant within each session. 


\section{Apparatus}

E-Prime 2.1 (Psychology Software Tools, Pittsburgh) running on a PC (Dell Precision) was used for stimulus presentation and data collection. The participants were seated approximately $50 \mathrm{~cm}$ from a 17 -inch Dell color monitor. Their task (Stroop task) was to identify the color of the letter-strings presented on the screen as quickly and accurately as possible while ignoring their meanings. To this end, the participants were instructed to fixate the white cross ("+"), which appeared in the center of the (black) screen for $500 \mathrm{~ms}$. The cross was then replaced by a letter-string that continued to be displayed until the participant responded (or until $3500 \mathrm{~ms}$ had elapsed). After this response, a new stimulus appeared on the screen, again replacing the fixation point and beginning the next trial. The response-stimulus interval was $1 \mathrm{~s}$ [5]. The participants responded using a keyboard placed on a table between the participant and the monitor. The keys were labeled with colored stickers, with key "1" representing red, key "2" representing green, key "3" representing "blue" and key "4" representing "yellow".

Before the beginning of the experimental block in the first Stroop session, the participants practiced learning which key on the keyboard represented each color (key-matching practice trials). In these 48 practice trials, strings of asterisks presented in the four colors (e.g., ***, ***) were used (instead of the experimental stimuli, see above).

\section{General Procedure}

Participants performed the Stroop task twice. In Session, all participants performed the task alone. In Session 2, they performed the task either alone or in the presence of a humanoid robot with which they had previously (right before the start of Session 2) interacted either negatively ("bad robot") or positively ("good robot") based on a series of five topics that they selected at random among seven (taken from [6]) presented on a piece of paper in a bucket (e.g., "Name three things you and your partner have in common", "What do you value most in friendship"). In the "bad robot" condition, the robot responded with contempt, a lack of 
empathy toward the participant and an unwillingness to answer. In the "good robot" condition, the robot responded in a nice way with empathy (see the script of the two conditions below, Table S1). The interaction always followed the same pre-established script, the operator having only to choose when to launch a given sequence. In the "alone" condition, participants described a picture of a landscape, a task that occupied the same amount of time as participants in the two other conditions. After the interaction/break, all participants performed the Stroop task (Session 2) in the presence of the bad versus good robot positioned in front of them (to their right on the edge of their peripheral vision) (figure S1). The robot watched participants $60 \%$ of the time by turning the head according to a pre-established motor script. To avoid any effect of human presence, the experimenter left the room during the Stroop performance in both sessions and in all conditions [7].

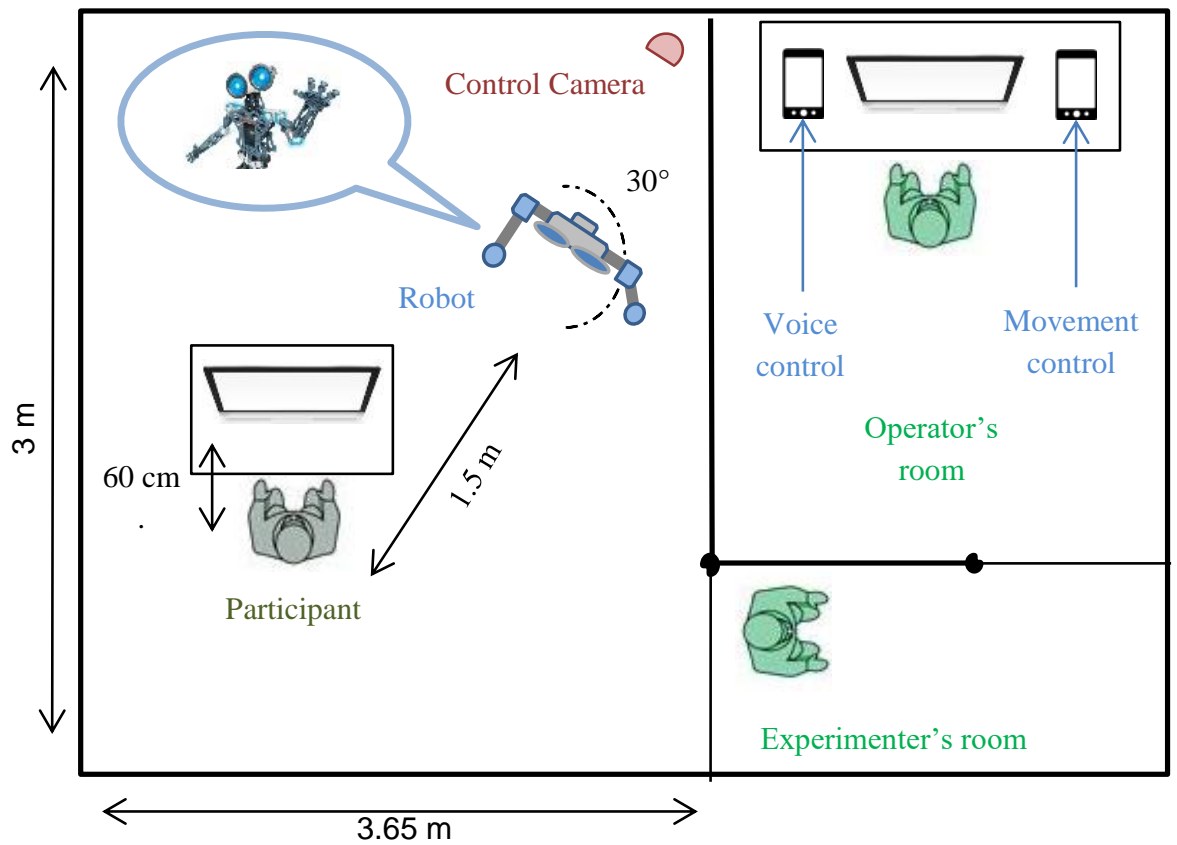

Figure S1 presents the experimental installation. We used a Meccanoid ${ }^{\mathrm{G} 15 \mathrm{KS}}$ animated at distance by a human operator using two smartphones for the control of the robot's gestures and speech. In the two presence conditions, the robot was positioned in front of participants (to their right on the edge of their peripheral vision) and watched them $60 \%$ of the time by turning the head according to a pre-established script. 
Table S1. Verbal exchange script.

\begin{tabular}{|c|c|c|}
\hline \multirow[t]{2}{*}{ Participant's Questions } & \multicolumn{2}{|l|}{ Robot Responses } \\
\hline & Positive Interaction & Negative Interaction \\
\hline $\begin{array}{l}\text { What would constitute a } \\
\text { "perfect" day for you? }\end{array}$ & $\begin{array}{l}\text { My ideal "perfect" day would be to meet people } \\
\text { like you outside to learn new things. }\end{array}$ & $\begin{array}{l}\text { I do not have a } \\
\text { "perfect" day, this } \\
\text { question does not make } \\
\text { sense. }\end{array}$ \\
\hline $\begin{array}{l}\text { Name three things you and } \\
\text { your partner appear to have in } \\
\text { common. }\end{array}$ & We have arms, two eyes and we are both nice. & $\begin{array}{l}\text { We are very different; I } \\
\text { do not see any common } \\
\text { points between us. }\end{array}$ \\
\hline $\begin{array}{l}\text { For what in your life do you } \\
\text { feel most grateful }\end{array}$ & $\begin{array}{l}\text { To meet and discuss with people, to have moments } \\
\text { of exchanges like this one, all this is very pleasant. }\end{array}$ & $\begin{array}{l}\text { I enjoy doing analysis } \\
\text { and evaluating } \\
\text { programs but you } \\
\text { would not understand. }\end{array}$ \\
\hline $\begin{array}{l}\text { If you had to wake up } \\
\text { tomorrow having gained a } \\
\text { quality or skill, what would it } \\
\text { be? }\end{array}$ & $\begin{array}{l}\text { To be able to have humor, it is difficult for me, the } \\
\text { only joke that I know is the story of a robot who } \\
\text { enters a bar. The bartender asks "What do you } \\
\text { want to drink? I need something that relaxes me a } \\
\text { bit". The bartender serves him a screwdriver... } \\
\text { Okay, it's not very funny. }\end{array}$ & $\begin{array}{l}\text { To be able to create } \\
\text { other robots to have } \\
\text { interesting } \\
\text { conversations. }\end{array}$ \\
\hline $\begin{array}{l}\text { Complete this sentence: "I } \\
\text { wish I had someone with } \\
\text { whom I could share..." }\end{array}$ & Good times and be able to talk about everything. & $\begin{array}{l}\text { This question seems too } \\
\text { personal for me to } \\
\text { speak with you. }\end{array}$ \\
\hline $\begin{array}{l}\text { What do you value most in } \\
\text { friendship? }\end{array}$ & $\begin{array}{l}\text { Sharing and trust, moreover I think we could } \\
\text { become friends. }\end{array}$ & $\begin{array}{l}\text { I do not value } \\
\text { friendship. }\end{array}$ \\
\hline $\begin{array}{l}\text { If you were going to become } \\
\text { a close friend with your } \\
\text { partner, please share what } \\
\text { would be important for him or } \\
\text { her to know. }\end{array}$ & I already like him(her) a lot. & That I'm bored. \\
\hline \multicolumn{3}{|l|}{ Robot's Questions } \\
\hline \multicolumn{3}{|c|}{ When did you last sing to yourself? To someone else? } \\
\hline \multicolumn{3}{|c|}{$\begin{array}{l}\text { If a crystal ball could tell you the truth about yourself, your life, the future, or anything else, what would you } \\
\text { want to know? }\end{array}$} \\
\hline \multicolumn{3}{|c|}{ Is there anything you would dream of doing? } \\
\hline \multicolumn{3}{|c|}{ What is your most treasured memory? } \\
\hline Tell your partner something th & you like about them already. & \\
\hline
\end{tabular}


We used a wizard of Oz paradigm [2] to control the robot. The robot was a Meccanoid G15 KS. To ensure a good audibility his headphone has been replaced by a JBL clip. We chose the Meccanoid to avoid the uncanny valley effect [8]. Participants could have felt discomfort in the presence of a human look like robot [9]. According to Duffy's classification [9] the robot could be placed to the center of the three extremities of the anthropomorphism view. Referring to the head of the robot, the "Human" extremity corresponds to an as-closeas-possible design to the human head. The "Iconic" corresponds to an expressive head with the minimum of features. Finally, the "Abstract" head refers to a functional design of the robot head. The robot was piloted by two smartphones connected in Bluetooth. Movements were controlled by a Motorola G 4G. Sounds were controlled by a LG optimus 2x connected to the JBL speaker. Both smartphones were powered by android. Voices have been designed with Voxal by $\mathrm{NCH}$ Software using the Pixie voice module. A hidden control camera was present in the room to ensure a good control over movements and responses for the wizard of Oz paradigm.

Anthropomorphic inferences. At the end of the experiment, participants completed The Robotic Social Attributes Scale (RoSAS) [10] scale to measure people's judgments of the social attributes of robots. The RoSAS scale was made of three constructs: perceived warmth (e.g., "happy"); perceived competence (e.g., "capable"); and perceived discomfort (e.g., "scary"). For each dimension, participants rated whether they agreed or disagreed (from 1 to 9) to attribute related characteristics to the robot being present.

Human-Robot Distance. Participants also filled out the humanness scale based on Haslam's dehumanization taxonomy [11] made of four dimensions. Two items illustrate the attribution of human traits: human uniqueness (e.g., moral sensibility), and human nature (e.g., interpersonal warmth). The two others dimensions illustrate the deprivation of human characteristics: animalistic dehumanization (e.g., irrationality), and mechanistic 
dehumanization (e.g., inertness). Again, for each dimension, participants rated whether they agreed or disagreed (from 1 to 9 ) to attribute the related characteristics to the robot being present.

Likeability. Finally, participants filled out the Godspeed III Likeability bi-dimensional scale [12] to measure their negative-positive evaluations of the robot being present (e.g. "unfriendly/friendly" from 1 to 9).

\section{Results $^{1}$}

Three participants were excluded of the analysis because they did not follow instructions either in the Stroop task (use of the two hands instead of the right hand only, conducting to more than $15 \%$ errors) or in the Robot interaction (no responses to the robot's questions), or because of technical errors (Robot interruption). Two participants were excluded due to extreme response times (RT) in the first session according to Cook's distances [13].

Errors occurred on $1.25 \%$ (152 trials out of 12367) of the trials and were analyzed independently (all $p_{\mathrm{s}}>.05$ ). Correct trials with a RT lower or higher than 3 standard deviations per experimental condition for each participant were considered outliers and also excluded from the RT analyses (1.24\% of the trials).

The RT data were examined using a 2 (Session 1 vs. 2) by 3 (Condition: Alone, positive vs. negative interaction with the robot) ANOVA, with Stroop interference (RTs for colorincongruent words minus RTs for color-neutral words, see Table S2) in session 1 and 2 as within-subject factor, and Condition as between-subject factor.

Stroop interference. The Session by Condition interaction was significant $(F(2,51)=3.91$, $\left.p=.026, \eta^{2}{ }_{p}=.13\right)$. Contrasts showed a Stroop interference reduction of $43 \mathrm{~ms}$ but only in the Negative interaction condition $\left(\mathrm{SE}=10.67, p^{<.001)}\right.$. Comparisons on the computed score of Stroop interference evolution between sessions (Stroop interference in session 1 minus Stroop interference in session 2) showed that the positive interaction condition did not differ from the

\footnotetext{
${ }^{1}$ All datas' tables are available online at osf.io/djgqh.
} 
control condition $(t(51)=-.324, p=.747$, Cohen's $d=0.48)$ whereas the negative HRI condition differed from the positive HRI and control conditions averaged $(t(51)=2.679$, $p=.010$, Cohen's $d=1.99$ ). (see Figure 1B in the main text). The effect was not due to a random difference in Session 1 between condition $\left(F(2,51)=2.226, p=.118, \eta_{p}^{2}=.08\right)$.

Table S2. Mean correct response times (in milliseconds), standard deviations (in parentheses) and error rates as a function of the type of stimuli, session, and group.

\begin{tabular}{crr|rr|rr} 
& \multicolumn{2}{c|}{ Alone } & \multicolumn{2}{r}{ Positive Interaction } & \multicolumn{2}{r}{ Negative Interaction } \\
\cline { 2 - 7 } & Session 1 & Session 2 & Session 1 & Session 2 & Session 1 & Session 2 \\
\hline Color-incongruent & 726 & 714 & 744 & 758 & 788 & 749 \\
& $(98)$ & $(128)$ & $(74)$ & $(67)$ & $(113)$ & $(93)$ \\
& 1.85 & 0.93 & 1.82 & 1.48 & 1.63 & 2.08 \\
\hline Color-neutral words & 688 & 686 & 712 & 730 & 725 & 729 \\
& $(67)$ & $(88)$ & $(67)$ & $(70)$ & $(110)$ & $(86)$ \\
\hline Stroop interference & 1.62 & 1.04 & 2.08 & 1.65 & 1.81 & 1.65 \\
\hline Stroop reduction & $+38^{*}$ & $+28^{*}$ & $+32^{*}$ & $+28^{*}$ & $+63^{*}$ & $+20^{*}$ \\
\hline
\end{tabular}

*:p<.05; ns: not significant.

Anthropomorphic inferences. The data related to the Robotic Social Attributes Scale were examined using a MANOVA with their different constructs entered simultaneously as dependent variables, and the two robot presence conditions (Negative vs. Positive interaction) as independent variable. As expected, results showed that the robot in the Positive interaction condition was seen as warmer (Cronbach's alpha $=.84)$ than in the Negative interaction condition $\left(F(1,40)=12.71, p=.001, \eta_{p}^{2}=.25\right)$ but there were no differences in terms of Competence $($ Cronbach's alpha $=.82)$ arguing for an equivalent evaluation of robot capacities across condition ${ }^{2}$. Regression analyses showed that perceived Warmth had no significant

\footnotetext{
${ }^{2}$ However, regression analysis showed a positive correlation between Warmth and Competence attribution, controlling for Discomfort $\left(b=.867, t=6.53, p<.001, \mathrm{r}^{2}=.52\right)$. This effect was independent of the group ( $\left.\mathrm{p}>.05\right)$.
} 
effect on Stroop interference reduction between session $(F(1,40)=.839, p=.365)$. More surprisingly, there was no difference in term of Discomfort (Cronbach's alpha $=.76$ ) between condition $\left(F(1,40)=.614, p=.438, \eta_{p}^{2}=.016\right)$. However, we found an interaction between Robot conditions and the perceived Discomfort $\left(b=-12.58, t=-2.09, p=.043, r^{2}=.10\right)^{3}$. In the Negative interaction condition, the more participants attributed Discomfort traits to the robot, the greater was the improvement of Stroop performance $\left(b=15.15, t=2.14, p=.048, r^{2}=.34\right)$.

Human-Robot Distance. As for RoSAS, data related to the Humanization scale were examined using MANOVA with the same parameters. Results showed that participants attributed more Human Nature (Cronbach's alpha $=.83)$ traits $\left(F(1,40)=6.48, p=.015, \eta^{2} p\right.$ $=.14)$ and less Mechanical Dehumanization traits $\left(F(1,40)=5.2, p=.028, \eta_{p}^{2}=.12\right)$ to the robot in the Positive interaction condition than in the Negative interaction condition. However there was no difference in terms of Human Uniqueness (Cronbach's alpha $=.87$ ) and Animalistic Dehumanization (Cronbach's alpha $=.76$ ) traits (all $p s>.05)$. Regression analyses showed that the perception of Mechanical Dehumanization (Cronbach's alpha = .8) traits $(b=11.35, t=2.43$, $p=.02, r^{2}=.13$ ) was correlated positively to the improvement in Stroop performance. Concomitant with these observations, the perception of Animal Dehumanization traits tended to be positively correlated to the improvement in Stroop performance in both conditions $\left(b=9.31, t=1.9, p=.064, r^{2}=.085\right)$.

Likeability. As expected, results on the Godspeed III Likeability bi-dimensional scale (Cronbach's alpha $=.96$ ) showed that participants found the robot in the Positive condition more friendly and pleasant than in the Negative condition $\left(F(1,46)=16.62, p<.001, \eta_{p}^{2}=.30\right)$.

\section{Supplemental references}

\footnotetext{
${ }^{3}$ The model including Robot conditions and perceived Discomfort as separated IVs (model's $r^{2}=.14$ ) showed only an effect of Robot conditions $(b=-18.85, \mathrm{t}=-2.46, \mathrm{p}=.019)$ arguing for a moderating influence of perceived Discomfort on the improvement of Stroop performance by Robot conditions effect.
} 
1. B. R. Duffy, Anthropomorphism and the social robot. Robotics Auton. Syst. 42, 177190 (2003).

2. M. Bella, B. Hanington, Universal Methods of design (Rockport Publishers, 2012).

3. M. Salem, F. Eyssel, K. Rohlfing, S. Kopp, F. Joublin, To err is human (-like): Effects of robot gesture on perceived anthropomorphism and likability. Int. J. Soc. Robotics 5, 313-323 (2013).

4. B. New, C. Pallier, M. Brysbaert, L. Ferrand, Lexique 2: A new French lexical database. Behav. Res. Methods Instrum. Comput. 36, 516-524 (2004).

5. D. Sharma, R. Booth, R. Brown, P. Huguet, Exploring the temporal dynamics of social facilitation in the Stroop task. Psychon. Bull. Rev. 17, 52-58 (2010).

6. A. Aron, E. Melinat, E. N. Aron, R. D. Vallone, R. J. Bator, The experimental generation of interpersonal closeness: A procedure and some preliminary findings. Pers. Soc. Psychol. Bull. 23, 363-377 (1997).

7. B. Hanington, B. Martin, Universal methods of design: 100 ways to research complex problems, develop innovative ideas, and design effective solutions (Rockport Publishers, 2012).

8. M. Mori, The uncanny Valley. Energy 7, 33-35 (1970)

9. B. R. Duffy, Anthropomorphism and the social robot. Robotics Auton. Syst. 42, 177-190 (2003).

10. C. M. Carpinella, A. B. Wyman, M. A. Perez, S. J. Stroessner, The robotic social attributes scale (RoSAS): development and validation, in Proceedings of the 2017 ACM/IEEE International Conference on Human-Robot Interaction (2017), pp. 254-262.

11. N. Haslam, S. Loughnan, Dehumanization and infrahumanization. Annu. Rev. Psychol. 65, 399-423 (2014). 
12. C. Bartneck, E. Croft, D. Kulic, S. Zoghbi, Measurement instruments for the anthropomorphism, animacy, likeability, perceived intelligence, and perceived safety of robots. Int. J. Soc. Robotics 1, 71-81 (2009).

13. K. S. Kannan, K. Manoj, Outlier detection in multivariate data. J. Appl. Math. Decis. Sci. 9, 2317-2324 (2015). 